\title{
Trends and challenges in long-term care in Europe
}

\author{
UDK: 616-082(4) \\ doi: 10.3935/rsp.v26i2.1655
}

\section{INTRODUCTION}

The $21^{\text {st }}$ century is a century of older people; the society is becoming long-lived. We are witnessing remarkable demographic changes; people are healthier, have higher quality of life and consequently live longer, which results in important social consequences at the individual level, as well as at the level of families and countries (see Filipovič Hrast \& Hlebec, 2015). In the next five decades, according to the latest demographic projections of Eurostat, the structure of the population will change radically. The proportion of the oldest Europeans (80 years and over) is expected to rise from 5\% in 2016 to $13 \%$ in 2070, while the old-age dependency ratio of older people will almost double in this period. Europe is expected to increase public expenditure on long-term care from $1.6 \%$ to $2.7 \%$ of GDP (European Commission, 2018). These trends will have a significant impact on the organization and financial sustainability of long-term care systems. We can expect an increase in the proportion of people who will need long-term care and a decrease in the proportion of those giving care, both formal and informal.

How national systems of long-term care are organized across Europe and what challenges are ahead is well described and analysed in a recent study on national policies in different European countries (35) prepared by the European Commission (Spasova et al., 2018). In the paper, we present main challenges and trends, identified by the mentioned study as those common to many of European countries: interinstitutional and geographical fragmentation of long-term care provision, trends toward prioritizing home care and a high incidence and expansion of informal care.

\section{FRAGMENTATION OF LONG- TERM CARE PROVISION}

In a number of European countries, long-term care has evolved from social assistance schemes, rather than from health care systems. Therefore, means-testing and out-of-pocket payments are present at varying degrees in all countries, contributing to quite a varied picture in terms of the financing mix of care (state, family or market) (Rodrigues \& Nies, 2013). Longterm care is typically funded from different sources like general taxation, obligatory social security, voluntary private insurance or out-of-pocket payments (European Commission, 2014). The extent of public and private financing varies highly between countries and a significant share is still paid out of pocket by users (European Commission, 2016). Partially because of its roots in social assistance, the governance of long-term care is much more decentralized and fragmented, with regional or local levels of government playing a much greater role in financing or regulating the sector (Rodrigues \& Nies, 2013). In terms of what is financed publicly, this basically differs according to the type of service and where the service is delivered. There are three types of services, which are relevant 
here': nursing care, domestic care, board, and lodging in institutional care (European Commission, 2016).

Nursing care is mostly covered under health-financing arrangements and domestic care is often not financed publicly (but public coverage may be offered based on means testing), except in the countries that offer comprehensive long-term care (the Netherlands, Sweden). Board and lodging costs for the recipients of care in long-term care institutions are mostly financed publicly for low-income people eligible to targeted assistance (mostly means tested). As board and lodging costs are a high cost component of long-term care, private financing means that cost sharing is a significant part of long-term care financing (European Commission, 2016).

Expenditure on long-term care in terms of GDP has been increasing over the past 20 years in many European countries and is nowadays quite heterogeneous. Currently, Nordic and Continental countries are among the leaders in the expenditure in long-term care, while Eastern European countries score the lowest values (Spasova et al., 2018). Total public spending on long-term care (including both the health and social care components) accounted for $1.7 \%$ of GDP on average across OECD countries in 2015 (see Figure 1). At $3.7 \%$ of GDP, the highest spender was the Netherlands, where public expenditure on long-term care was around double the OECD average. At the other end of the scale, Hungary, Estonia, Poland, Israel and Latvia allocated less than $0.5 \%$ of their GDP to the public provision of long-term care (OECD, 2017). Universal systems tend to be more generous in principle and thus devote a bigger share of their GDP to publicly funded long-term care (e.g. Sweden, Denmark, and the Netherlands) (Rodrigues \& Nies, 2013).

Figure 1

Long-term care expenditure (health and social components) by government and compulsory insurance schemes, as a share of GDP (2015 or nearest year)

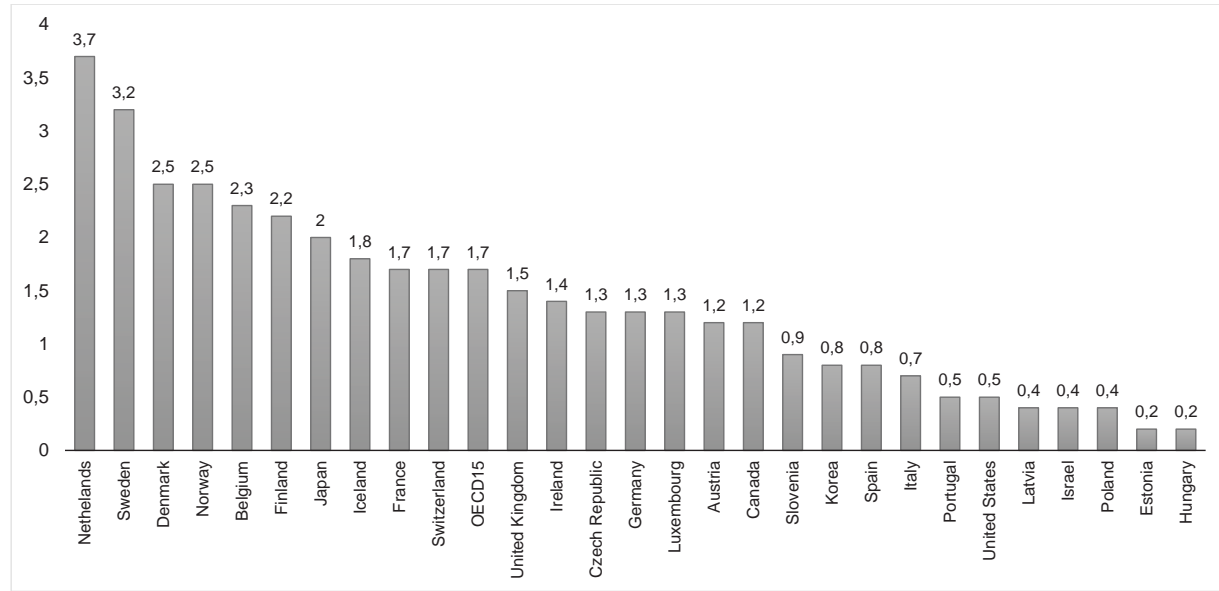

Note: Retrieved from OECD Health Statistics 2017.

${ }^{1}$ Otherwise, long-term care can be provided in-kind, as an allowance paid to the family carer or as a cash benefit for the care recipient. In-kind services can be nursing or ADL services (like domestic care) provided at home, can consist of services which can also have a respite function for he carer, such as day care, and furthermore can include institutional care provision such as in nursing home and palliative care (Colombo, Llena-Nozal, Mercier \& Tjadens, 2011). 
We can also observe a horizontal divide between health and social aspects of longterm care provision. The health system is responsible for the care provided by health professionals (i.e. nursing care), while social sector usually organizes services related to supporting the care-dependent person in the activities of daily living (i.e. domestic care). Few countries organize their system in a way which integrates health and social care horizontally (e.g. Denmark, Ireland and Poland). In most countries, this horizontal split between the health and social sectors is accompanied by a vertical division of responsibilities, with powers attributed at different institutional levels: national, regional and local. Such a horizontal division may lead to a lack of coordination between entities, which can have adverse effects for the recipient: e.g. waiting periods, administrative procedures, fragmentation of services, and a high risk of non-take up (Spasova et al., 2018).

Anyway, the complexity of long-term care systems and the diversity between countries can be illustrated by groups and types of countries that are similar in terms of their characteristics. There are several different typologies of long-term care systems (see Bettio \& Plantenga, 2004; Kraus et al., 2010; Colombo et al., 2011; Nies, Leichsenring \& Mak, 2013). The typology developed by the European Commission (2016) presented below is an extension of the typology by Kraus et al. (2010). It includes the following three dimensions: the mode of financing, the levels of spending and the extent of use of formal vs. informal care. After such a classification, the authors identified five typical groups of countries (European Commission, 2016). The characteristics of these groups are outlined in the Table 1.
Table 1

Typology of long-term care systems (European Commission, 2016)

\begin{tabular}{|c|c|}
\hline $\begin{array}{l}\text { Group of } \\
\text { countries }\end{array}$ & Characteristics of the group \\
\hline $\begin{array}{l}\text { Denmark, the } \\
\text { Netherlands } \\
\text { and Sweden }\end{array}$ & $\begin{array}{l}\text { Finance public provision of } \\
\text { long-term care by general } \\
\text { revenue allocations to local } \\
\text { authorities, have high public } \\
\text { and low private spending on } \\
\text { formal care, offer modest cash } \\
\text { benefits and have low use and } \\
\text { high informal care support. }\end{array}$ \\
\hline $\begin{array}{l}\text { Belgium, } \\
\text { the Czech } \\
\text { Republic, } \\
\text { Germany, } \\
\text { Slovakia and } \\
\text { Luxembourg }\end{array}$ & $\begin{array}{l}\text { Provide for an obligatory } \\
\text { social insurance against long- } \\
\text { term care risks financed from } \\
\text { contributions. Their system } \\
\text { is characterized by medium } \\
\text { public and low private formal } \\
\text { care spending, high use and } \\
\text { high informal care support, } \\
\text { and modest cash benefits. }\end{array}$ \\
\hline $\begin{array}{l}\text { Austria, } \\
\text { England, } \\
\text { Finland, } \\
\text { France, } \\
\text { Slovenia, Spain } \\
\text { and Ireland }\end{array}$ & $\begin{array}{l}\text { Have medium public coverage } \\
\text { against long-term care risks } \\
\text { financed from contributions } \\
\text { or general revenue. They are } \\
\text { medium spenders in terms of } \\
\text { public and private formal care } \\
\text { financing, have a high use of } \\
\text { and support for informal care, } \\
\text { and high to moderate cash } \\
\text { benefits. }\end{array}$ \\
\hline $\begin{array}{l}\text { Hungary, Italy, } \\
\text { Greece, Poland } \\
\text { and Portugal }\end{array}$ & $\begin{array}{l}\text { Provide modest social } \\
\text { insurance against long- } \\
\text { term care risks. They are low } \\
\text { spenders in terms of public } \\
\text { and high spenders in terms of } \\
\text { private formal care financing. } \\
\text { The use of informal care is } \\
\text { high, while support is relatively } \\
\text { low, as is the use of cash } \\
\text { benefits. }\end{array}$ \\
\hline $\begin{array}{l}\text { Bulgaria, } \\
\text { Cyprus, } \\
\text { Estonia, } \\
\text { Lithuania, } \\
\text { Latvia, Malta, } \\
\text { Romania and } \\
\text { Croatia }\end{array}$ & $\begin{array}{l}\text { Have little social insurance } \\
\text { against long-term care risks } \\
\text { and correspondingly low } \\
\text { public spending on formal } \\
\text { care. The use is high and there } \\
\text { is little to no informal care } \\
\text { support. In addition, cash } \\
\text { benefits are modest/low. }\end{array}$ \\
\hline
\end{tabular}

Note: Retrieved from European Commission, 2016, p. 172-174. 


\section{PRIORITIZING HOME CARE}

Given a choice between care in an institution (in a residential setting) or at home, most people would prefer the latter (European Commission, 2007). The Principle 18 of the European Pillar of Social Rights on long term care states that "Everyone has the right to affordable long-term care services of good quality, in particular homecare and community-based services." Expectations about the possibilities of aging at home have grown with a strengthened role of community care, notions of care coordination and possibly integration of care delivery, the technological innovations for distant monitoring, and with modern, more complex forms of service delivery available in person's home. The growing demand for (home) care services already exceeds the available supply, and this trend is expected to continue in the following decades. This trend is explained by aforementioned demographic changes (aging population, dependency ratios), but also by social changes (female labour market participation, smaller family units), changes in epidemiology, increase in science and technical innovations, changes in people's expectations and wishes, and policy priorities (deinstitutionalization, community-based solutions) (Tarricone \& Tsouros 2008).

The majority of EU countries (i.e. Austria, Germany, Denmark, Spain, Finland, France, Norway, Sweden, Slovenia and others (Spasova et al., 2018)) are prioritizing home care in their policy documents and national strategies, by pursuing the concept of "ageing in place." The arguments to strengthening community care are focused on the people's quality of life and protection of fundamental human rights (Ilinca, Leichsenring \& Rodrigues, 2015). The focus on delivering care is transforming, shifting towards a person-centred care and highlighting the dig- nity, autonomy, values and choice of the people. Services therefore need to change in order to be more flexible in meeting people's needs.

Deinstitutionalisation and community living are generally accepted as principles that support policy making. A growing body of literature suggests that community-based interventions lead to better outcomes for users at lower or comparable costs (Tarricone \& Tsouros, 2008). Evidence suggests that older adults have better health outcomes if appropriate preventative care is provided to them in the community (Beswick et al., 2008). Alternatives to institutional care are therefore emerging, in a form of different community services, intermediate care, day care, together with the initiative to support informal carers, integrate care, and provide prevention and rehabilitation. But, as reported by Leichsenring, Billings \& Nies (2013), this process is slow. The evidence of coordinating care around users can be identified, but is often limited to individual short-term projects. Despite deinstitutionalisation tendencies and clear policy goals, in some cases economic reasons and measures to ensure financial sustainability, especially austerity measures, steer direct policies in another direction by obstructing access to care. This means that eligibility criteria get stricter, and home care focuses more towards persons with the most severe needs, leaving heavy burden to informal carers. Home care therefore remains underdeveloped in numerous countries, especially in Southern and Eastern Europe where only a limited number of people in need can access it. All Nordic and some Continental countries (the Netherlands, Germany, France, and Belgium) are more successful in that area (Spasova et al., 2018).

Across OECD countries, $13 \%$ of people aged 65 or more on average received long-term care in 2015. The percentage 
of recipients varies considerably among countries, with only $2.1 \%$ in Portugal to more than 20\% in Switzerland (see Figure 2) (OECD, 2017). The percentage of community care recipients corresponds with service availability; it is the highest in Nordic and some Continental countries. People aged over 80 make up on average more than half of all recipients (OECD, 2017). In countries with available trend data, we can observe a rise in the proportion of long-term care recipients (65+) at home in the past ten years, with the exception of Estonia and Finland (OECD, 2017). drigues, Hoffmann, Gasior \& Marin, 2009; Naiditich, Trifantafillou, Di Santo, Carretero \& Hirsch Durrett, 2013; Verbeek-Oudijk, Woittiez, Eggink \& Putman, 2014; Zigante, 2018). Estimates suggest that informal carers provide around $80 \%$ of long-term care (Hoffmann \& Rodrigues, 2010) and that informal carers account for between $10 \%$ and $25 \%$ of the total population in Europe (Colombo et al., 2011). The proportions vary greatly across countries and depend on how informal care is defined and measured. This strongly supports the most recent study on informal care in Europe (Zigante, 2018),

\section{Figure 2}

The share of people aged 65 or more / 80 or more, receiving home care across EU countries (2016 or closest year)

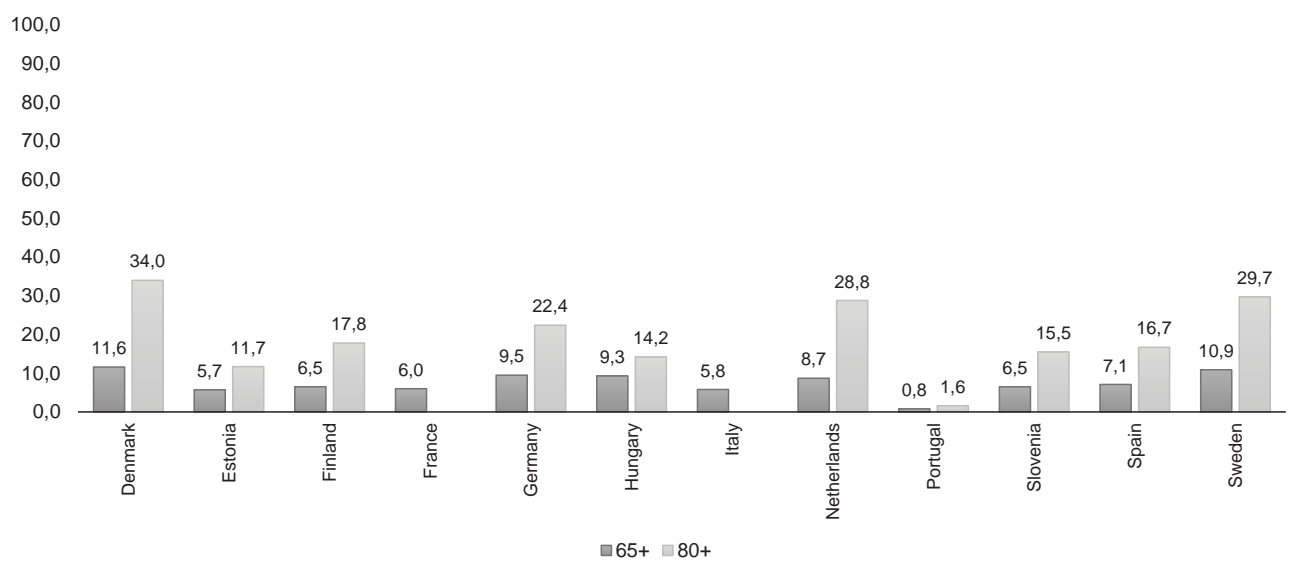

Note: Retrieved from stats.oecd.org. No data for people aged 80 or older are available in France and Italy.

\section{HIGH INCIDENCE AND EXPANSION OF INFORMAL CARE}

Numerous international studies and authors illustrate informal care ${ }^{2}$ as the backbone or cornerstone of care (Huber, Ro- where this diversity is shown using the latest EQLS data ${ }^{3}$ (see Figure 3). The lowest percentage (around 10\%) is detected in Romania, the Czech Republic, Austria, Bulgaria and Ireland, and the highest (around 35\%) in Greece, followed by Belgium (around $30 \%$ ) and Malta (around 25\%).

${ }^{2}$ There is no standard definition of informal care (Zigante, 2018). The most frequently used definition describes it as care provided by family members, friends or neighbours to a person who needs help and support at home. The care they provide is lay and usually unpaid

${ }^{3}$ According to EQLS research, an informal carer is someone who provides care at least once per week which is, compared to other studies where this limit is usually set to 20 hours per week, a low threshold (Zigante, 2018). 
Figure 3

Informal carers as a \% of total adult population, EQLS 2016

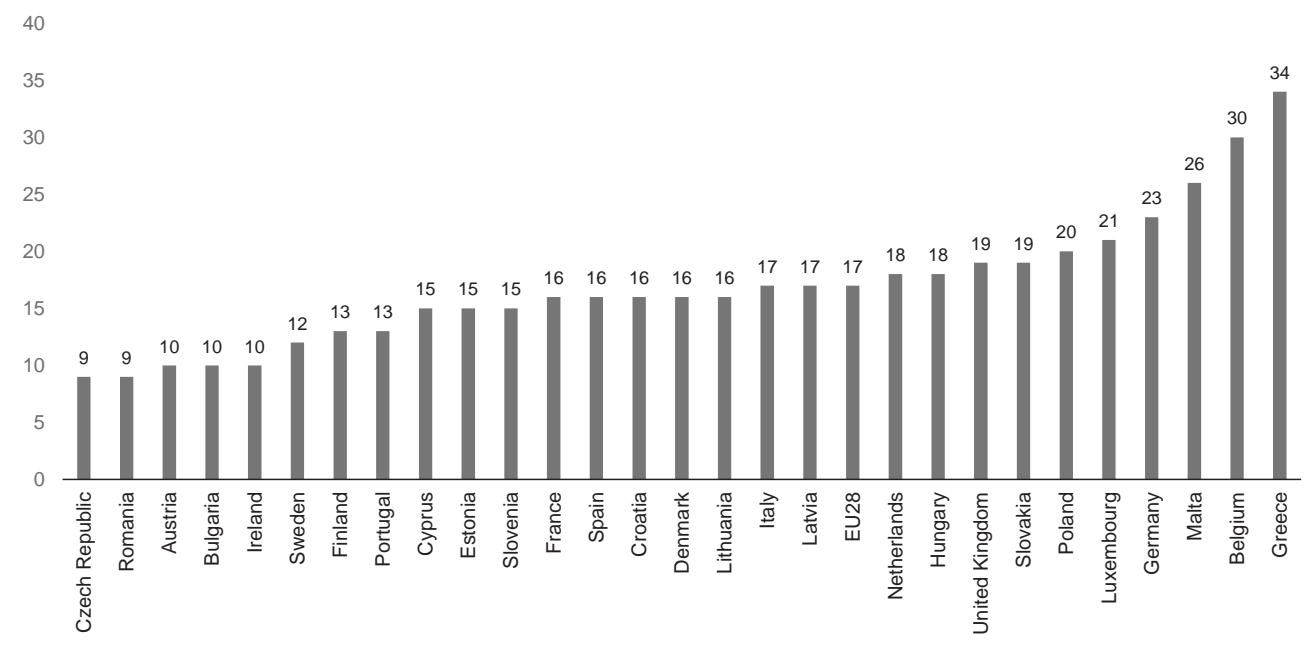

Note: Retrieved from Zigante (2018), EQLS 2016.

The main reason for the expansion and high incidence of informal care is a shortage of accessible formal long-term care facilities. Other reasons include the poor quality of long-term care (e.g. Italy, Macedonia, the United Kingdom), the highly biased subsidization of long-term care (Cyprus), the shortage of institutional and community services (e.g. Croatia), the non-affordability of long-term care (e.g. Italy, Macedonia), and the traditional model of intergenerational and familial relations (Spasova et al., 2018).

Despite cultural changes, new attitudes and relative progress in the distribution of caring tasks, women (mainly wives and children) continue to take responsibility for and carry out the bulk of caring (Spasova et al., 2018). EQLS research shows that in all countries (expect in two) more women than men provide care. The gender gap in caring is especially visible in Belgium where $13 \%$ more women than men provide care (Zigante, 2018). The time spent caring can have a negative impact on the employment rate of carers, their financial well-being and, therefore, indirectly on their tax receipts. Informal carers may have to reduce the working hours at their workplace or stop working altogether. This puts them at a higher risk of poverty, often through the reduced work and lower pension entitlements (European Commission, 2016).

Countries in EU set out a number of policies which recognize and to some extent 'formalize' the role of informal carers with the aim of supporting carers and reducing a potential negative impact that providing care can have on them. This takes place through payments (cash allowances, cash for care policies), social security (pension and health insurance), legislation (recognition of status and rights to receive assessment as a carer), statutory employment related rights and training/certification of skills schemes (Zigante, 2018).

Countries vary greatly in the extent to which the informal carer is supported by public policies, and as it is stated in the report by Spasova et al. (2018), only a limited 
number of countries have well-developed services tailored to informal carers. In this sense, the recommendation is to continue the support to informal carers for providing care through features such as cash benefits, allowances, specific rights, respite leave, counselling and information, and at the same time to minimize any disincentives for their labour market participation (European Commission, 2016). The support and enabling of informal carers should be recognized as a key policy goal in relation to long-term care in Europe in the coming decades (Zigante, 2018).

\section{CONCLUSION}

This documentation highlights key trends in long-term care in EU countries which are trying to find cost-effective user-friendly solutions in this field. Notwithstanding that the organization, funding and types of long-term care offered vary greatly among European countries, the policy documents (European Commission, 2014; European Commission, 2016; Spasova et al., 2018) all very similarly identify main elements of a response to this pressing issue. Policies are generally directed to assuring financial sustainability, distancing from residential care by strengthening community care, care coordination and integration between health and social services, assuring prevention, rehabilitation and re-enablement, and to improving the status of informal carers as the backbone of long-term care. Last but not least, it is important not to discuss only the quantity and financing of long-term care, but also its quality and impact. This should have implication for the protection of fundamental human rights and dignity of people needing care. Care should not be just about giving people whatever they want, it should also be about empowering them, improving their experience of care, considering their values, desires, family situations and lifestyles.

\section{LITERATURE}

Beswick, A. D., Rees, K., Dieppe, P., Ayis, S., Gooberman-Hill, R., Horwood, J., \& Ebrahim, S. (2008). Complex interventions to improve physical function and maintain independent living in elderly people: A systematic review and meta-analysis. Lancet, 371(9614), 725-735. https:// doi.org/10.1016/S0140-6736(08)60342-6

Bettio, F., \& Plantenga, J. (2004). Comparing care regimes in Europe. Feminist Economics, 10(1), 85-113. https://doi. org/10.1080/1354570042000198245

Colombo, F., Llena-Nozal, A., Mercier, J., \& Tjadens, F. (2011). Help Wanted? Providing and Paying for Long-Term Care. Paris: OECD Publishing.

European Commission. (2007). Special Eurobarometer-Health and long-term care in the European Union. Brussels: European Commission.

European Commission. (2014). Adequate social protection for long-term care needs in an ageing society. Brussels: European Commission.

European Commission, Directorate-General for Economic and Financial Affairs. (2018). The 2018 Ageing Report, Economic \& Budgetary projections for the 28 EU Member States (2016-2070). Brussels: European Commission.

European Commission, Directorate-General for Economic and Financial Affairs, \& Economic Policy Committee. (2016). Joint Report in Health Care and Long-Term Care Systems and Fiscal Sustainability and its country reports. Brussels: European Commission.

Filipovič Hrast, M., \& Hlebec, V. (2015). Staranje prebivalstva: oskrba, blaginja in solidarnost. Ljubljana: Fakulteta za družbene vede.

Hoffmann, F., \& Rodrigues, R. (2010). Informal carers: Who takes care of them? Vienna: European Centre for Social Welfare Policy and Research.

Huber, M., Rodrigues, R., Hoffmann, F., Gasior, K., \& Marin, B. (2009). Facts and figures on longterm care. Europe and North America. Vienna: European Centre for Social Welfare Policy and Research.

Ilinca, S., Leichsenring, K., \& Rodrigues, R. (2015). From care in homes to care at home: European experiences with (de)institutionalisation in longterm care. Vienna: European Centre for Social Welfare Policy and Research.

Kraus, M., Riedel, M., Mot, E., Willeme, P., Röhrling, G., \& Czypionka, T. (2010). A typology of longterm care systems in Europe. ENEPRI Research Report No 91. 
Leichsenring, K., Billings, J., \& Nies, H. (2013). Improving policy and practice in long-term care. In K. Leichsenring, J. Billings \& H. Nies (Eds.), Long-term care in Europe. Improving policy and practice (pp. 325-337). London: Palgrave Macmillan.

Naiditich, M., Trifantafillou, J., Di Santo, P., Carretero, S., \& Hirsch Durrett, E. (2013). User perspectives in long-term care and the role of informal carers. In K. Leichsenring, J. Billings \& H. Nies (Eds.), Long-term care in Europe. Improving policy and practice (pp. 45-81). London: Palgrave Macmillan.

Nies, H., Leichsenring, K., \& Mak, S. (2013). The emerging identity of long-term care systems in Europe. In K. Leichsenring, J. Billings \& H. Nies (Eds.), Long-term care in Europe. Improving policy and practice (pp. 19-45). London: Palgrave Macmillan.

Organisation for Economic Co-operation and Development. (2017). Health at a Glance 2017: OECD Indicators. Paris: OECD Publishing.

Rodrigues, R., \& Nies, H. (2013). Making sense of differences - The mixed economy of funding and delivering long-term care. In K. Leichsenring, J. Billings \& H. Nies (Eds.), Long-term care in
Europe. Improving policy and practice (pp. 191213). London: Palgrave Macmillan.

Spasova, S., Baeten, R., Coster, S., Ghailani, D., Peňa-Casas, R., \& Vanhercke, B. (2018). Challenges in long-term care in Europe. A study of national policies 2018. Brussels: European Commission.

Verbeek-Oudijk, D., Woittiez, I., Eggink, E., \& Putman, L. (2014). Who cares in Europe? A comparison of long-term care for the over-50s in sixteen European countries. Haag: The Netherlands Institute for Social Research.

Zigante, V. (2018). Informal care in Europe. Exploring formalisation, availability and quality. Luxembourg: Publications Office of the European Union.

Tarricone, R., \& Tsouros, A. D. (2008). Home care in Europe. Geneva: WHO.

\section{Mag. Mateja Nagode,}

Inštitut RS za socialno varstvo

Lea Lebar,

Inštitut RS za socialno varstvo 